\title{
Doses resulting from the inhalation of ITER generated tritiated dust*
}

\author{
H. MAUBERT ${ }^{1}$, L. DI PACE ${ }^{2}$
}

(Manuscript received 1st June 2007, accepted 21 September 2007)

\begin{abstract}
Dust particles generated in the ITER Tokamak may include some tritium. The coefficients derived to evaluate the doses resulting from the inhalation of the usual forms of tritium (gaseous, tritiated water, organic form) are not adequate for tritiated dust. This paper is a short literature study about the assessment of tritiated dust dose coefficients and their significance in worker, population and environmental protection for ITER

RÉSUMÉ Doses résultant de l'inhalation de particules tritiées générées dans l'installation ITER.

Les particules générées dans le Tokamak ITER peuvent contenir du tritium. Les coefficients de doses habituellement utilises pour évaluer les doses résultant de l'inhalation concernent les formes moléculaires, aqueuses ou organiques ne paraissent pas adaptées aux poussières tritiées. Ce texte fait état d'une étude bibliographique sur le sujet et tire les conséquences de l'émission de poussières tritiées pour la radioprotection des travailleurs d'ITER et des populations environnantes.
\end{abstract}

Keywords: dust / tritium / dose coefficient / inhalation / lung / fusion / Tokamak

\section{Objectives}

Although in the design and operation every precaution is taken in order to confine radioactive materials, it cannot be definitely excluded that during the operational life of ITER the atmosphere inside the buildings, including operative areas as well, may get contaminated with small amounts of tritium and radioactive dust. After detritiation and filtering, a part of this contamination could be released to the environment. This is a concern for the protection of workers and the population. In some cases dust particles will also include tritium. The coefficients derived to

* This report was prepared as an account of work undertaken within the framework of ITER Transitional Arrangements (ITA). These are conducted by the participants: the European Atomic Energy Community, India, Japan, the People's Republic of China, the Republic of Korea, the Russian Federation, and the United States of America, under the auspices of the International Atomic Energy Agency. The views and opinions expressed herein do not necessarily reflect those of the Participants to the ITA, the IAEA or any agency thereof. Dissemination of the information in this paper is governed by the applicable terms of the former ITER EDA Agreement.

1 ITER Organisation, Cadarache Joint Work site, 13108 Saint-Paul-lez-Durance, France.

2 ENEA FUS/TEC, Via Enrico Fermi 45, 00044 Frascati, Rome, Italy. 
evaluate the doses resulting from the inhalation of the usual forms of tritium (gaseous, tritiated water, organic form) are presumably not adequate for tritiated dust. The objective of this paper is to summarize the work already done on this subject and to assess the relative impact of the tritium contained in the particles compared to the total impact of ITER tritium releases.

\section{Characterization and behaviour of particles}

For dose coefficients evaluation the relevant parameters of tritiated dust are the size, and their chemical characteristics. The size controls the ability of the particles to be inhaled, their deposition place in the human respiratory tract and therefore their ability to be cleaned by natural processes. The chemical characteristics, namely the solubility of the particles, governs the velocity at which tritium will be absorbed in the body fluids (e.g. blood) and distributed throughout the body via the circulatory system. For overall dose assessment and eventual derived limits in air, the specific radioactivity in dust whether it comes from tritium or other radionuclides is also important.

The process of dust formation in Tokamaks is described in detail in reference (Piet and Federici, 1996) and shown in Figure 1.

Dust may be carbonaceous dust or metallic, Be, W, stainless steel, depending on the composition of PFCs. In JET and TFTR, co-deposition with tritium has been found significant only with carbon.

Particles with aerodynamic diameter ${ }^{3}$ below $10 \mu \mathrm{m}$ are inhalable. The coarser particles are deposited mainly in the anterior nasal passage and are cleared in approximately 1 day (Di Pace and Patel, 2005). The remaining airways of head and neck are covered by a fluid lining, the mucus, which is constantly cleared in a few minutes to the pharynx and swallowed. Much of the material deposited in the bronchial and bronchiolar region is cleared in a few hours by the mucus. These transfer mechanisms clear the particles through the gut. Tritiated particles absorbed in the gastro-intestinal are mostly excreted via faeces. The finer particles, less than a few $\mu \mathrm{m}$, may reach the alveoli where the clearance is much slower and it is mostly governed through the release of tritium as dissolution occurs from the particle surface.

It is estimated that in the alveolar interstitial region, there is about $80 \%$ retention at 50 days and $50 \%$ at one year.

For tritium the health protection guidelines are based on the behavior of tritiated water (HTO). Tritiated water is absorbed into body fluid and

\footnotetext{
3 Aerodynamic diameter $=$ diameter of a unit density sphere having the same settling velocity of the non-spherical particle.
} 

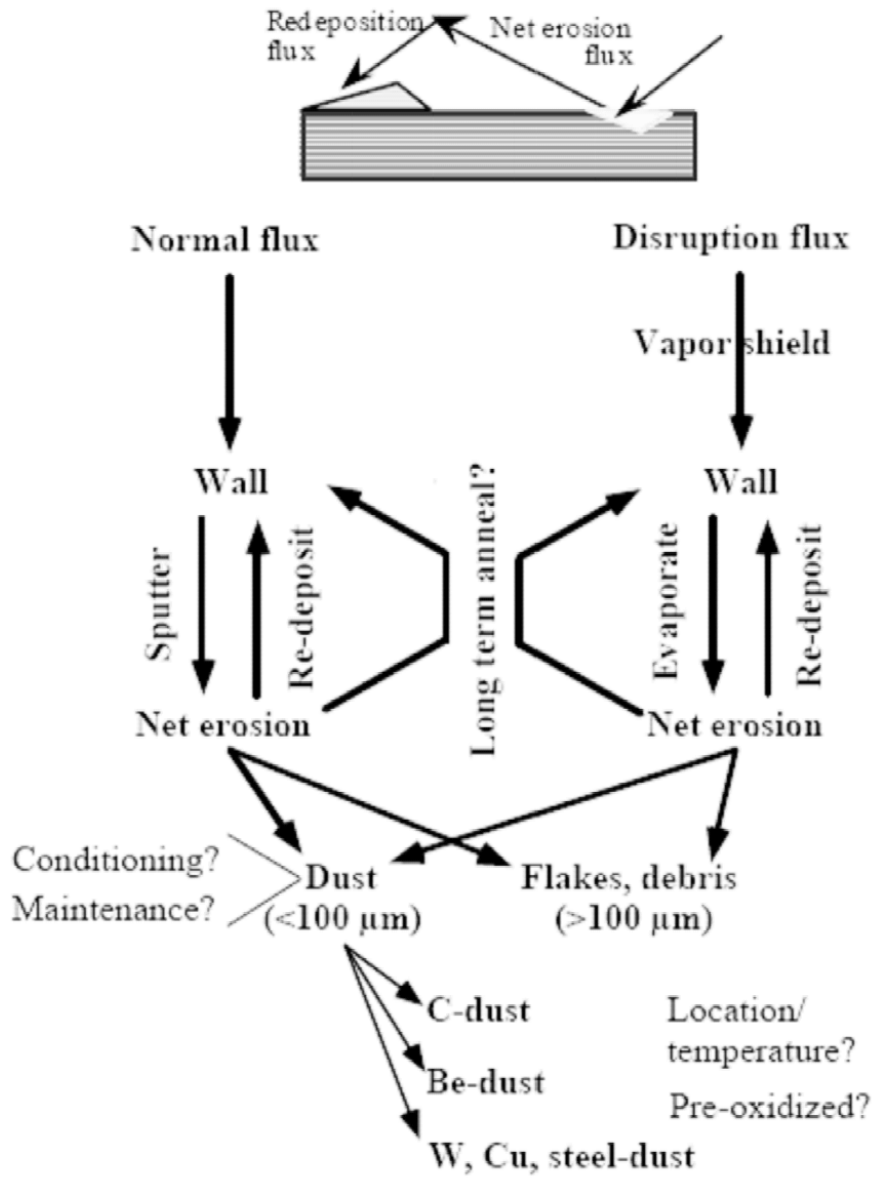

Figure 1 - Plasma wall interactions leading to dust formation.

Interactions plasma/paroi conduisant la formation de poussière.

instantaneously distributed in all soft tissues. According to the biokinetic model based on ICRP Publications 68 (1995) and 78 (1998), tritium as HTO is cleared from the body with a effective biological half life of 10 days, and that $3 \%$ will be cleared with a half life of 40 days, but for OBT the fraction is $50 \%$ for both rates.

Tritiated particles will remain in the lungs for a period of time and will release tritium to the body at a rate depending on their solubility. Compared to tritiated water, these characteristics may change the effective dose coefficient and the 
committed equivalent dose coefficient to the lung. The steps (Patel and Letellier, 2006) commonly used to derive dose coefficient for tritiated dusts are to determine their solubility in a simulant lung serum of in vitro, and then to use a respiratory tract model. In most cases the particles considered in this paper possess a matrix such as carbon, metals, stainless steel, which is insoluble or very weakly soluble in water or body fluids. Therefore the term dissolution of particles here refers to the dissolution of tritium which is associated to the particles.

The dust characterization from the 1999 JET shutdown showed that the mean aerodynamic diameter expresses as radioactivity (AMAD) was around $4 \mu \mathrm{m}$ (Di Pace, 2003). According to Figure 9 of (Di Pace, 2003), which summarizes the results of the particle deposition made by the ICRP respiratory tract model (ICRP, 1994), approximately $75 \%$ of particles of that size would be retained in upper respiratory tract.

The dissolution tests conducted in NRPB (Di Pace, 2003) on carbon particles from JET concluded that the dissolution of tritium could be described by a twocomponent process: a fast dissolution rate from a limited fraction and a very slow process for the remainder. The fast dissolution fraction was 0.003 for fine particles and 0.05 for coarse particles. The fast dissolution half times were around two minutes for both fractions and the slow ones were 1925 days for the fine particles and 110 days for the coarse particles.

Further tests from HPA performed on JET particles (Hodgson et al., 2006) refined these findings with a three components fit of the experimental results. For example for the most soluble materials, the parameters describing the dissolution were three fractions of $0.0645,0.086$ and 0.85 with respective T1/2 of $2 \mathrm{~min}$, 1.3 days and 456 days.

The effective dose coefficients derived from these series of experiments are summarized in Table I.

The dose coefficients, $\mathrm{Sv} \mathrm{Bq}{ }^{-1}$, are computed assuming that the values found for in vitro dissolution rates were the same as the values for absorption rate from lungs to blood as defined in ICRP Publication 66. However, the graphite matrix of these particles is, essentially insoluble and so it is possible that a large fraction of the tritium remains trapped delivering dose to the lung if the beta particles are able to escape the encapsulating matrix.

By assuming that the long term component is insoluble and its fraction equal to 1 , the dose coefficients computed above may be in the worst case under estimated (Hodgson et al., 2006) by a factor of 2.7 for the most soluble material (SG1). In the case of SG2 particles, the least soluble, the factor is just 1.1. 
TABLE I

Effective dose coefficients for different species of tritiated dusts. Coefficient de dose efficace pour différentes sortes de poussières tritiées.

\begin{tabular}{ll}
\hline \multicolumn{1}{c}{ species } & Effective dose coefficient (Sv/Bq) \\
\hline HTO & $1.8 \times 10^{-11}$ \\
OBT & $4.1 \times 10^{-11}$ \\
$\begin{array}{l}\text { Coarse particles, dissolved tritium assumed to behave like HTO, and like } \\
\text { OBT }\end{array}$ & $2.6 \times 10^{-11}$ and $2.8 \times 10^{-11}$ \\
$\begin{array}{l}\text { Fine particles, dissolved tritium assumed to behave like HTO and like OBT } \\
\text { (no difference) }\end{array}$ & $9.9 \times 10^{-11}$ \\
\hline $\begin{array}{l}\text { HPA experiments, range for } 3 \text { samples (SG1), } 1 \mu \mathrm{m} \text { particles } \\
\text { HPA experiments, range for } 3 \text { samples (SG2), } 1 \mu \mathrm{m} \text { particles }\end{array}$ & $8.4 \times 10^{-11}$ to $2.0 \times 10^{-10}$ \\
\hline HPA experiments, range for 3 samples (SG1), $5 \mu \mathrm{m}$ particles & $2.6 \times 10^{-10}$ to $2.7 \times 10^{-10}$ \\
\hline HPA experiments, range for 3 samples (SG2), $5 \mu \mathrm{m}$ particles & $4.9 \times 10^{-11}$ to $1.1 \times 10^{-10}$ \\
\hline
\end{tabular}

Note: SG1 and SG2 denote material collected from two different JET tile material (SG1 = carbon fiber composite, SG2 = carbon graphite)

TABLE II

Self absorption fraction of beta energy calculated for metal tritides (hafnium Hf, titanium Ti and zirconium $\mathbf{Z r}$ ).

Fraction d'auto-absorption de l'énergie bêta calculée pour des métaux tritiés (hafnium Hf, titanium Ti et zirconium $\mathbf{Z r}$ ).

\begin{tabular}{lccc}
\hline & HfT & TiT & ZrT \\
\hline $\mathrm{CMD}(\mu \mathrm{m})^{1}$ & 1.04 & 0.95 & 0.32 \\
Density $\left(\mathrm{g} \mathrm{cm}^{-3}\right)$ & 11.68 & 4.6 & 5.6 \\
$\mathrm{SAF}_{\mathrm{e}}{ }^{2}$ & 0.042 & 0.33 & 0.39 \\
\hline
\end{tabular}

${ }^{1} \mathrm{CMD}=$ count mean diameter; ${ }^{2} \mathrm{SAF}_{\mathrm{e}}=$ self-absorption factor; the fraction of energy escaping from metal tritide particle.

However it is likely that these dose coefficients have been overestimated due to the decreased tritium concentration at the particle surface, because the dissolution occurs more easily from the particle outer layers. The dosimetric model assumes, on the other hand, a uniform tritium distribution in the particle, while, in the above hypothesis, the self absorption is more effective even for particles as small a $1 \mu \mathrm{m}$. That is due to the fact that the beta emission of tritium has a very low energy (19 keV max and $5.7 \mathrm{keV}$ as average).

Self absorption factors of beta energy calculated by a mathematical model (Kropf et al., 1998) for metal tritides (hafnium Hf, titanium Ti and zirconium $\mathrm{Zr}$ ) with different dimensions are shown in Table II (Zhou and Cheng, 2004). 
For particles (HfT and TiT) with close dimension (CMD 1 $\mu \mathrm{m}$ ), the effect of the material density on the Self Absorption Factor is remarkable as a result of beta energy shielding.

Besides the study of JET particles, other studies mention the solubility in lung fluid simulant of tritium trapped in a variety of matrixes: TFTR particles, titanium (Di Pace, 2003; Cheng et al., 1999), hafnium (Zhou and Cheng, 2003; Cheng and Zhou, 2002), beryllium, graphite, titanium, iron hydroxide and zirconium (Richardson and Hong, 2001).

The comparison of dissolution of JET and TFTR particles is not conclusive as the characterization of the particles is not equivalent in the publications. However the tritium dissolution curves are similar in shape. For TFTR particles the dissolution rate ranged from $10^{-1}$ to $10^{-3}$ per day in the first few hours then decreased to $10^{-3}$ to $10^{-4}$ per day. 110 days after the beginning of the experiments $90 \%$ of the tritium retained in the particles. These data should not lead to modify the range of the dose coefficients indicated in Table I.

In vitro experiments conducted with titanium tritide showed different results than those conducted on JET particles (Cheng et al., 1997). The results showed that coarse particles (mean size $103 \mu \mathrm{m}$ ) dissolved more slowly than fine particles (mean size $0.95 \mu \mathrm{m}$ ). That is more consistent with the theory that the dissolution rate for smaller particles is higher because of the larger surface-to-volume ratio. As written, the inverse was observed for JET particles; that may be a result of different shape, porosity and specific surfaces of the particles for a given size. After 30 days, $5.1 \%$ of the titanium tritide coarse particles had been dissolved in the lung serum simulant. The dissolution half time was estimated at 361 days. The fine particles dissolved according to a two component decay curve. The fast proportion was $24 \%$ with a half time of about $1 \mathrm{~d}$ and the slow component had a half dissolution time of 33 days.

In vivo experiments have been conducted (Zhou and Cheng, 2003) by instilling particles of hafnium tritides in the trachea of rats. The particles had a count median diameter of $1.04 \mu \mathrm{m}$. In vitro and in vivo dissolution rates were evaluated and compared. The kinetic behavior was characterized by a two term exponential decay curve with biological half times of 4.9 and 1257 days. The fast dissolution fraction was $24.9 \%$. The effective dose coefficients for lung, liver and whole body were calculated to be $5.41 \times 10^{-10}, 6.0 \times 10^{-15}$ and $5.43 \times 10^{-10} \mathrm{~Sv} / \mathrm{Bq}$. The weighting factors were $0.12,0.05$ and 0.83 for lung, liver and other soft tissues respectively. This is about 30 times higher than the HTO dose coefficient $\left(1.8 \times 10^{-11} \mathrm{~Sv} / \mathrm{Bq}\right)$. Using the ICRP 66 model, and assuming the same lung burden of hafnium tritide the committed effective dose $\mathrm{E}(50)$ is estimated to be $9.95 \times 10^{-10} \mathrm{~Sv} / \mathrm{Bq}$. In another 


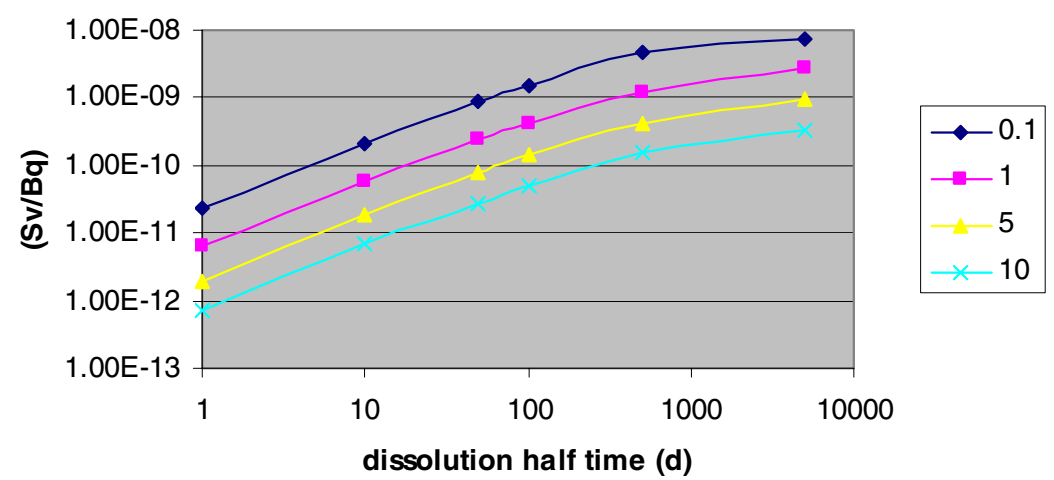

Figure 2 - Committed dose to alveolar tissue for different sizes (Activity Median Aerodynamic Diameter, AMAD) of particulate Be tritides (plotted from Richardson and Hong, 2001).

Dose engagée au tissu alvéolaire pour différentes tailles de particules de tritiure de berylium (diamètre aérodynamique médian en activité, DAMA) (d'après Richardson et Hong, 2001).

study (Cheng and Zhou, 2002) about the doses to lung from hafnium tritides based on ICRP model and on in vitro dissolution tests, committed effective doses coefficients ranged from $7.72 \times 10^{-10}$ to $1.04 \times 10^{-11} \mathrm{~Sv} / \mathrm{Bq}$ for particles with aerodynamic diameter ranging from 0.25 to $10 \mu \mathrm{m}$.

A calculation of the doses to lung has been performed (Richardson and Hong, 2001) for five different species of particles: beryllium, carbon, iron oxide, titanium and zirconium tritides. In this study a very detailed modeling of the alveolar tissue is made. The absorption of the beta particle emitted by the tritium in the particle itself and in the mucus and cells layers is taken into account.

The results for $\mathrm{BeT}_{0.03}$, plotted from Table III in (Richardson and Hong, 2001), are shown in Figure 2.

Table III gives a correction factor for particles other than $\mathrm{BeT}_{0.03}$.

If we apply these data to JET particles, considered to be tritiated carbon with an AMAD of $4 \mu \mathrm{m}$ and a dissolution half time of 2000 days, we find that the committed dose coefficient for the alveolar tissue would be around $8 \times 10^{-10} \mathrm{~Sv} / \mathrm{Bq}$.

\section{Summary on doses}

The highest effective dose coefficient mentioned in the studies reviewed above for Tokamaks particles, is $2.7 \times 10^{-10} \mathrm{~Sv} / \mathrm{Bq}$. That is about 15 times higher than the 
TABLE III

Average ratio of material dose coefficient to that of $\mathrm{BeT}_{0.03}$ (Richardson and Hong, 2001). Rapport moyen du coefficient de dose du matériel par rapport à celui du $\mathrm{BeT}_{\mathbf{0 , 0 3}}$ (Richardson et Hong, 2001).

\begin{tabular}{lcccc}
\hline \multicolumn{1}{r}{ Material } & \multicolumn{3}{c}{ AMAD $(\mu \mathrm{m})$} \\
\hline $\mathrm{BeT}_{0.03}$ & 0.1 & 1 & 5 & 10 \\
$\mathrm{CT}_{0.4}$ & 1 & 1 & 1 & 1 \\
$\mathrm{FeO}(\mathrm{OT})$ & 1.05 & 0.94 & 0.90 & 0.9 \\
$\mathrm{TiT}_{2}$ & 1.38 & 1.05 & 0.8 & 0.77 \\
$\mathrm{ZrT}_{2}$ & 1.36 & 1.04 & 0.83 & 0.78 \\
\hline
\end{tabular}

AMAD = activity median aerodynamic diameter

ICRP effective dose coefficient for tritiated water (HTO), $1.8 \times 10^{-11} \mathrm{~Sv} / \mathrm{Bq}$ and $\sim 7$ times the effective dose coefficient for organically bound tritium (OBT). For in vivo hafnium tritides experiments (Zhou and Cheng, 2003), the committed effective dose coefficient is estimated to be $5.43 \times 10^{-10} \mathrm{~Sv} / \mathrm{Bq}$ for the whole body.

Committed equivalent doses to lung calculated for different types of tritiated particles show coefficients up to approximately 30 times the HTO coefficient, but one should take into account that the tritiated particles uptake in the rats was through intratracheally instillation, hence by-passing the upper airways, where, according to the particle size, a remarkable fraction is retained through deposition.

\section{Consequences for ITER}

Activated dust is mainly produced in the vacuum vessel by plasma interaction with structures, and in a lesser manner by in-vessel maintenance. In vessel maintenance is remotely operated. The first action of maintenance is to clean as thoroughly as possible the inside of vacuum vessel from mobilizable dust. Normally the atmosphere of the vacuum vessel when it is vented, is filtrated and discharged to the stack and not inside the buildings. The plasma facing components when they are removed from the vacuum vessel to be refurbished of replaced are transported in sealed casks to the hot cells. The atmosphere inside the hot cells is also filtrated and purified before discharge to the stack. The rooms where people may work in the vicinity of the Tokamak or the hot cells are equipped with particulate monitors allowing an early detection of any loss of confinement. Therefore there is almost no possibility for workers to breathe air contaminated with tritiated particulates. 
In the calculation below is about the hypothetical case of a leak of the vacuum vessel venting air to a room. The aim of this calculation is to assess the dose that could result from such an event.

$5 \%$ of the tritium inventory (1000 g, conservative value (How, 2007)) in the vacuum vessel may be associated to carbon dust (Topilski, 2007). The limit for total C-dust mobilizable inventory within 1st confinement barrier is $200 \mathrm{~kg}$ (GSSR, 2004), then the tritium concentration is $50 \mathrm{~g}-\mathrm{T} / 200 \times 10^{3} \mathrm{~g}-\mathrm{C}_{\mathrm{dust}}=$ $0.00025\left(\mathrm{~g}-\mathrm{T} / \mathrm{g}-\mathrm{C}_{\text {dust }}\right)$, hence the $\mathrm{T}$ concentration in $\mathrm{C}_{\text {dust }}$ is $0.00025 \times$ $3.57831 \times 10^{+14} \mathrm{~Bq} / \mathrm{g} \sim 9 \times 10^{10} \mathrm{~Bq} / \mathrm{g}$, rounded to $10^{11} \mathrm{~Bq} / \mathrm{g}$.

The efficiency of in vessel dust cleaning is assumed to be $90 \%$, therefore the amount of mobilizable dust is $20 \mathrm{~kg}$. $0.1 \%$ of this amount could be lofted into the air (GSSR, 2004). The volume of the vacuum vessel is $1700 \mathrm{~m}^{3}$, and the efficiency of the first stage of filtration (HEPA filter) is 1000. Assuming that the dust is uniformely distributed in the vacuum vessel, the concentration of dust in the exhaust gas after filtration would be $1.2 \times 10^{-5} \mathrm{~g} \mathrm{~m}^{-3}$. With a specific activity of $10^{11} \mathrm{~Bq} \mathrm{~g}^{-1}$, and neglecting further dilution in the room atmosphere, the inhalation of $0.5 \mathrm{~m}^{3}$ (approximately $1 / 2$ hour stay, a maximum time before evacuation) of air would mean the inhalation of $5.9 \times 10^{5} \mathrm{~Bq}$. With a dose coefficient of $2.7 \times 10^{-10} \mathrm{~Sv} / \mathrm{Bq}$ the dose would be $0.16 \mathrm{mSv}$.

The ITER annual release (GSSR, 2004) for dust originating from the Tokamak has been estimated to be $0.25 \mathrm{~g} / \mathrm{y}$ at the stack, after the last stage of filtration. If all the dust is considered as tritiated dust it means that the release of tritium under particulate form would be $2.5 \times 10^{10} \mathrm{~Bq} / \mathrm{y}$. This is a negligible part of the release authorization which will be asked for ITER and which will be expressed in hundreds of TBq/year. In all cases, the dosimetric impact of routine releases will be less than $10 \mu \mathrm{Sv} / \mathrm{y}$; even with a dose coefficient 15 times that of HTO, the impact of tritiated dust is insignificant.

\section{REFERENCES}

Cheng Y.S., Dahl A.R., Jow H.N. (1997) Dissolution of Metal Tritides in a Simulated Lung Fluid, Health Phys. 73, 633-638.

Cheng Y.S., Snipes M.B., Wang Y.S., Jow H.N. (1999) Biokinetics and dosimetry of titanium tritide particles in the lung, Health Phys. 76, 120-128.

Cheng Y.S., Zhou Y. (2002) Dose estimate of inhaled hafnium tritide using the ICRP 66 lung Model, Health Phys. 82, 817-824.

Di Pace L. (2003) Literature study on the radiological hazards of tritiated dust and flakes. Final report, JW3-FT-5.12, 1 december 2003.

Di Pace L., Patel B. (2005) Factors affecting the inhalation dose from tritiated dust and flakes, Fusion Engineering and Design, Proceedings of the 23rd Symposium of Fusion Technology - SOFT 23, Volumes 75-79, November 2005, pp. 1181-1186. 
GSSR (2001) Generic Site Safety Report, Volume VI, Occupational Safety, ITER IDoMS No. G 84 RI 5 01-07-12 R 1.0, July 2001.

GSSR (2004) Generic Site Safety Report, Volume IV, Normal Operation, ITER IDoMS No. N 84 RI 1 R 0.2, July 2004.

GSSR (2005) Generic Site Safety Report, Volume IV, Normal Operation, ITER IDoMS No. N 84 RI 1 01-06-27 R1, February 2005.

Hodgson S.A., Scott J.E., Hodgson A. (2006) In vitro dissolution of tritium loaded particles from the JET fusion machine, RPD-DAR-02-2006, Health Protection Agency, UK, June 2006.

How J. (Ed.) (2007) Project Integration Document (PID), ITER_D_2234RH v 3.0, January 2007.

ICRP Publication 66 (1994) International Commission on Radiological Protection, Human Respiratory Tract Model for Radiological Protection, Ann. ICRP 24 (1/3).

ICRP Publication 68 (1995) International Commission on Radiological Protection, Doses coefficients for intakes of radionuclides by workers, Ann. ICRP 24 (4).

ICRP Publication 78 (1998) International Commission on Radiological Protection, Individual monitoring for individual exposure of workers, Ann. ICRP 27 (3-7).

Kropf R.F., Wang Y.S., Cheng Y.S. (1998) Self-absorption of tritium betas in metal tritide particles, Health Phys. 75, 398-404.

Patel B., Letellier E. (2006) Experimental determination of parameters relevant to radiological safety of JET tritiated dust, Draft report, JW3-FT-5.12, 31 May 2006.

Piet S.J., Federici G. (1996) ITER White Paper on Integrated Picture of In-Vessel Tritium and Dust, ITER IDoMS S 81 RI 13 96-06-28 W 1.4, 21 July 1996.

Richardson R.B., Hong A. (2001) Dose to lung from inhaled tritiated particles, Health Phys. 81, 313324.

Topilski L. (2007) Safety Analysis Data List, document ITER_D_24LSAE v. 2.0, 2007.

Zhou Y., Cheng Y.S. (2003) Dose assessment for inhaling hafnium particles based on laboratory rats study, Health Phys. 84, 469-476.

Zhou Y., Cheng Y.S. (2004) Dosimetry of Metal Tritide Particles as Evaluated by the ICRP 66 Model and a Biokinetic Model From Laboratory Rats, Health Phys. 86, 155-160. 